\title{
Trends in the Northeast dairy industry: Large-scale modern confinement feeding and management-intensive grazing
}

\author{
J. R. Winsten, ${ }^{* 1}$ C. D. Kerchner, $\dagger^{2}$ A. Richardson, $\dagger^{3}$ A. Lichau, $\dagger$ and J. M. Hyman $\dagger$ \\ *Winrock International, Little Rock, AR 72202 \\ †Department of Community Development and Applied Economics, University of Vermont, Burlington 05405
}

\begin{abstract}
This paper provides a summary of results from a recent survey of 987 dairy farmers in 4 northeastern US states. The survey results provide descriptive characteristics of the current state of dairy farming in the region, as well as farmer satisfaction levels, concerns, and plans for the future of their farming operations. The paper analyses characteristics of two increasingly important dairy production systems used in the Northeast. Averages from across the survey states (Maryland, Pennsylvania, New York, and Vermont) show that approximately $13 \%$ of dairy producers use management-intensive or rotational grazing and $7 \%$ use large, modern confinement systems with more than 300 cows. These more specialized production systems show many significant differences in farm and farmer characteristics, satisfaction levels, and plans for the future compared with farms using more traditional production systems. The changing structure of the dairy industry has potentially important implications for environmental quality, rural communities, and the food system.
\end{abstract}

Key words: dairy farming, confinement-feeding, management-intensive grazing, rotational grazing

\section{INTRODUCTION}

Dairy farming remains the largest agricultural sector in the northeastern United States. This industry has been under tremendous financial stress, however, and has undergone dramatic shifts in the past several decades. Because dairy farming has been the backbone of many agricultural rural communities in the region, the pressures and changes in this industry have the potential to cause significant changes far beyond the farm gate.

Received October 24, 2008.

Accepted December 29, 2009.

${ }^{1}$ Corresponding author: Jwinsten@winrock.org

${ }^{2}$ Current address: AgRefresh, PO Box 843, Burlington, VT 05401.

${ }^{3}$ Current address: Prescott Creeks Preservation, PO Box 3004, Prescott, AZ 86302.
The current national trend in dairy farming is consolidation into fewer, but larger, farms (MacDonald et al., 2007a,b), and this trend can be observed in the Northeast. The total number of dairy farms in the region (including New York, Vermont, Pennsylvania, Maryland, New Hampshire, Massachusetts, Rhode Island, Connecticut, and Maine) has decreased by $83 \%$ since 1960 (Figure 1). The number of milking cows in the region has decreased by $49 \%$ from approximately $2,948,000$ to $1,480,100$ head during this same period (Figure 2). Although the number of milking cows and dairy farms has steadily declined across the region, the average number of milking cows per farm has increased by almost 50\% (Blayney, 2002). Average milk production per cow has more than doubled over this period (Figure 3).

The pressures in the industry that are driving the trend toward fewer, larger dairy farms stem, in part, from lower cash margins per unit of milk sold (MacDonald et al., 2007a). In addition, the price that farmers receive for milk is greater in the Northeast compared with other regions because of greater fluid milk consumption. Large dairies in the Northeast can gain a revenue advantage relative to smaller operations because of the greater volume of milk sales (MacDonald et al., 2007a). The primary financial concern for many farmers is how to ensure that their operation will yield sufficient net farm income to support the living expenses for the family or families that own the farm. Larger herd sizes and greater per-cow milk production is a common way for farmers to address this concern.

When confronted with how best to deal with growth and farm viability issues, traditional dairy and livestock producers in the Northeast often find themselves at a crossroads. Although there are numerous and varied approaches that dairy farmers can take, this paper has a specific focus on two paths that a traditional farm can follow: 1) the creation of larger operations supported by confinement-feeding systems and 2) the creation of operations that attempt to reduce production costs using rotational grazing. Obviously, another path leads to exiting the milk production industry. Large numbers of 


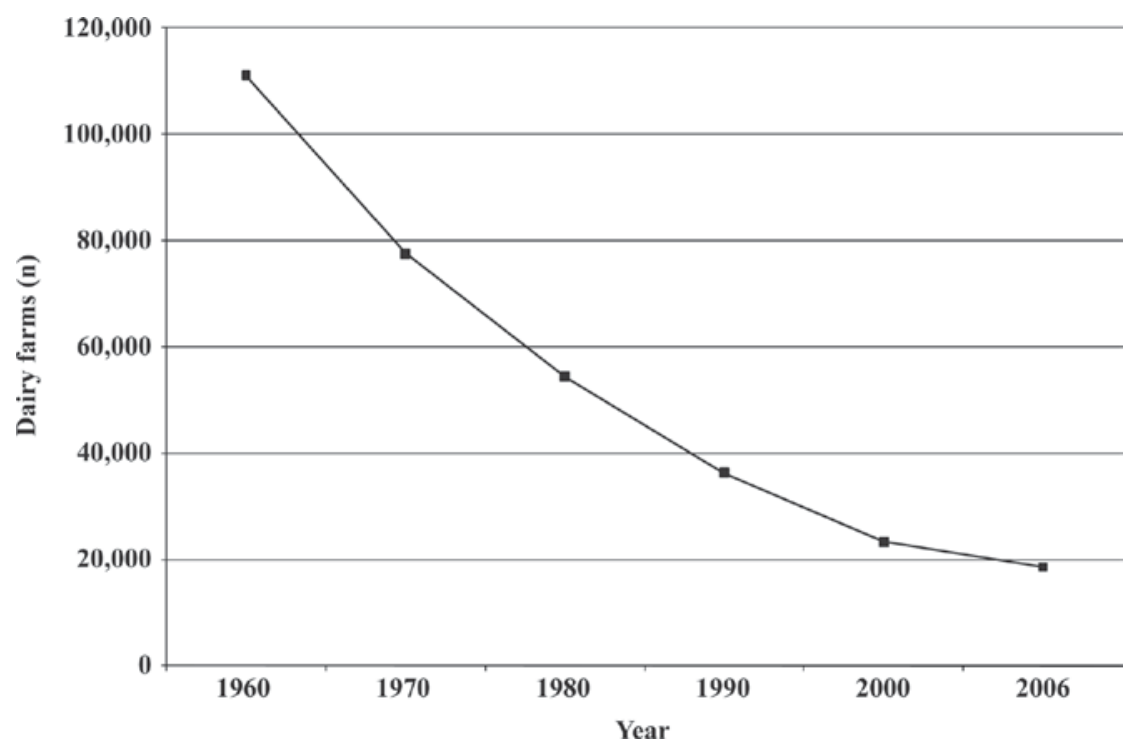

Figure 1. Total number of dairy farms in the Northeast, 1960 to 2006. Source: USDA National Agriculture Statistics Service (USDA NASS, 2009): Quick Stats, US and State Data, Dairy, for the states of New York, Vermont, Maryland, Pennsylvania, Rhode Island, Maine, Connecticut, New Hampshire, Massachusetts.

dairy farmers in the Northeast have followed this path in recent decades (Figure 1).

The most common model for larger scale dairy farm expansion is characterized by a confinement-feeding system using a TMR in a freestall barn with a modern milking parlor. Herd sizes for this type of dairy farm expansion are often several hundred cows or more, with the frequency of 1,000-head herds increasing. The potential exists for this production system, referred to in this paper as large, modern confinement (LMC), to generate substantial revenue by producing a large volume of milk. This is accomplished through maximizing milk production per cow across a large number of cows. The LMC system often produces a modest profit margin per unit of milk produced, but a sizable net farm income. To be successful, this system requires a high level of management ability across the primary areas of dairy farm management. These areas include animal husbandry, agronomy, human resources, and financial management. Having a large herd in one location requires increasing levels of environmental management as regulations become stricter.

The use of well-managed pasture; that is, rotational grazing or management-intensive grazing (MIG), as it

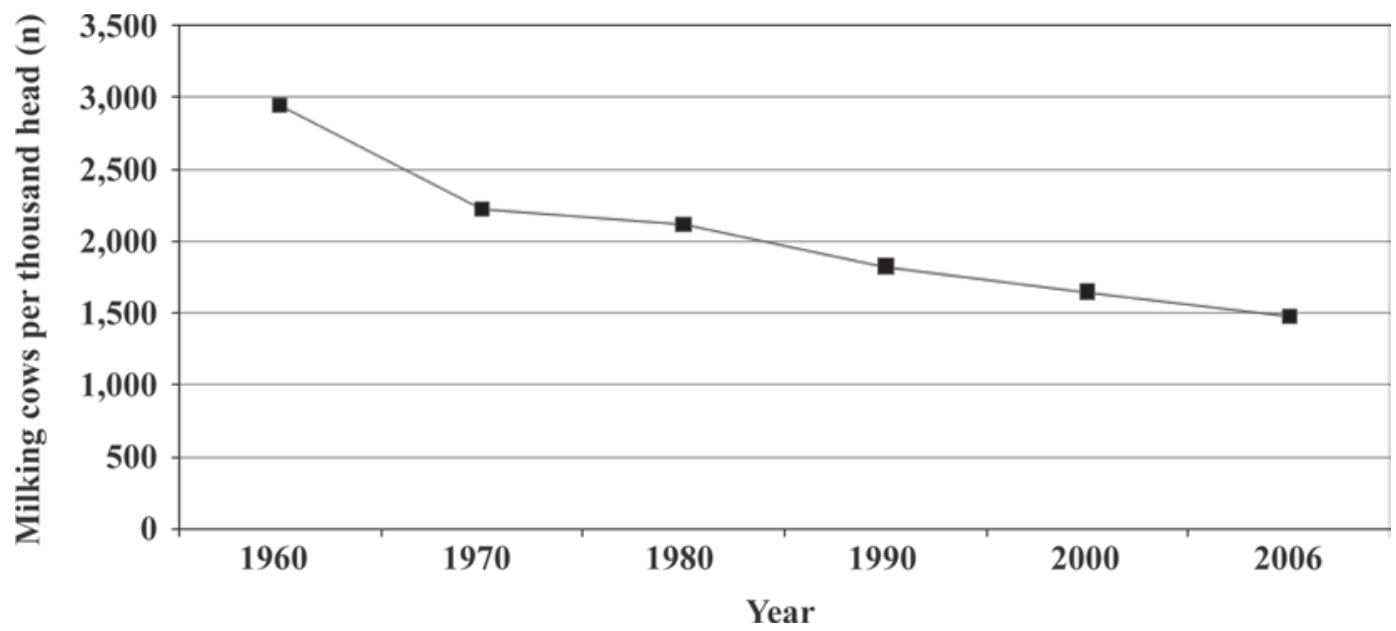

Figure 2. Total number of milk cows in the Northeast, 1960 to 2006. Source: USDA National Agriculture Statistics Service (USDA NASS, 2009): Milk Production, Disposition, and Income Annual Summary; USDA NASS: Milk Cows and Production, for the states of New York, Vermont, Maryland, Pennsylvania, Rhode Island, Maine, Connecticut, New Hampshire, Massachusetts. 


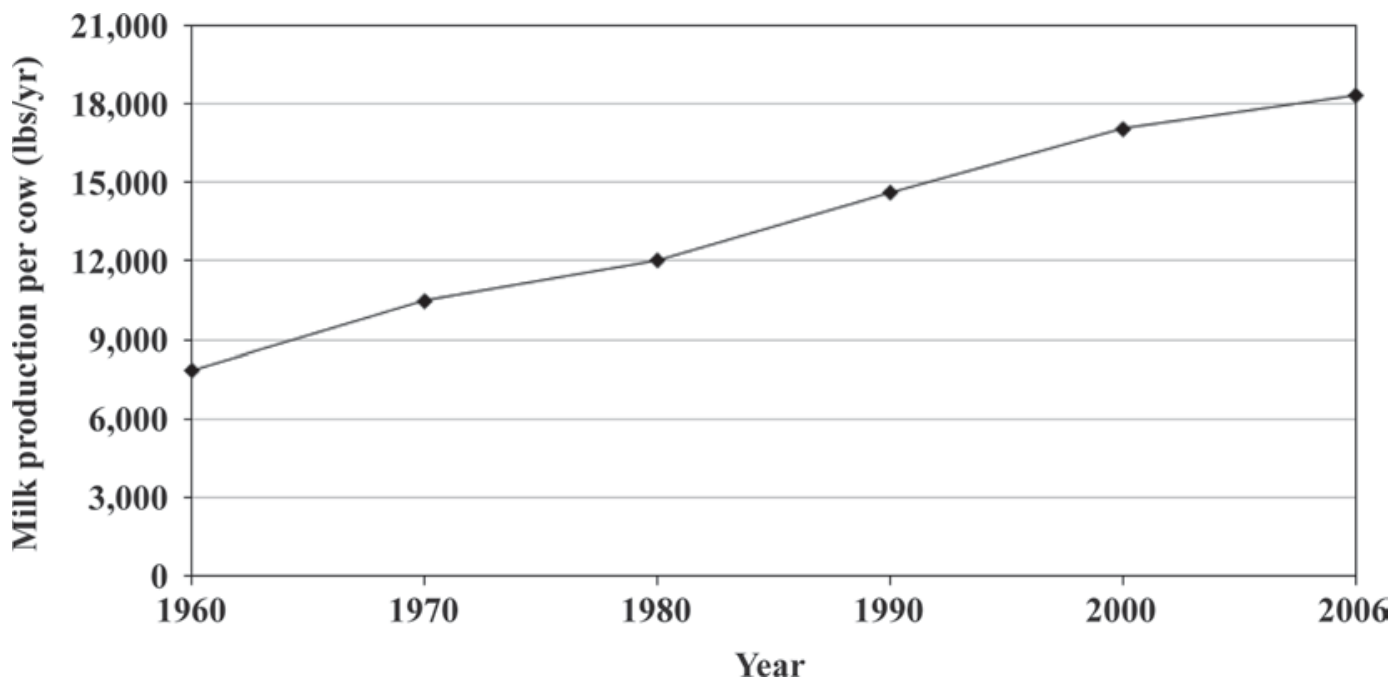

Figure 3. Average milk production per cow (lbs/yr) in the Northeast, 1960 to 2006. Source: USDA National Agriculture Statistics Service (USDA NASS, 2009): Milk Production, Disposition, and Income Annual Summary; USDA NASS: Milk Cows and Production.

is referred to in this paper, has the potential to increase the financial viability of small- and medium-sized farms by reducing fixed and operating costs of production (Winsten et al., 2000b). Farms using MIG have the potential to improve water quality and wildlife habitat relative to current agricultural land use (Paine et al., 2000; Renfrew and Ribic, 2001). Several studies have indicated that MIG has the potential to benefit rural communities (Jackson-Smith et al., 1996; Hassanein, 1999; Ostrom and Jackson-Smith, 2000), even though MIG farms may purchase fewer inputs per cow.

With regard to animal health and milk quality, numerous studies have found advantages to the use of pasture as a feed source for dairy cows. Berghaus et al. (2005) found that the use of pasture decreased the risk of hemorrhagic bowel syndrome in herds with a rolling herd average of $20,000 \mathrm{lbs}(9,072 \mathrm{~kg})$ or less, which most MIG herds have. Parker et al. (1993) found that herds on pasture had a lower incidence of hoof problems and eye disease relative to herds fed in confinement. Green et al. (2007) found that cows on rotated pastures had fewer cases of clinical mastitis relative to cows that were continuously grazed or housed during the dry period. Goldberg et al. (1992) found that herds under rotational grazing had lower somatic cell counts during the grazing season relative to continuous grazing or confinement housing. They also found that non-agalactiae streptococcal counts were significantly lower for rotational grazing herds during the grazing season. During the winter, when all herds were in confinement, there were no differences. Onyiro and Brotherstone (2008) found that cows housed on pasture had better scores for feet and leg health and locomotion versus cows in freestalls, straw yards, or slatted floors. Hernandez-Mendo et al.
(2007) found that cows housed on pasture showed less lameness than cows housed in freestall barns. Thomsen et al. (2006) found that Danish dairy herds that grazed in the summer had significantly lower mortality compared with herds that did not graze.

This paper, when compared with results from Winsten et al. (2000a), shows that the MIG system is being used by a small, but growing, percentage of dairy farmers in the Northeast. As the name implies, MIG is a production system that requires a high level of management to produce adequate income and profit from a pasture-based forage system. This article uses information and results from a 2007 survey of dairy farmers in the Northeast to help describe the current structure of the Northeast dairy industry, farmers' concerns, and plans for the future, as well as satisfaction levels with various aspects of their operations.

\section{MATERIALS AND METHODS}

\section{Survey Instrument}

Surveys were mailed to over 4,000 dairy farmers in 4 northeastern states (Vermont, New York, Pennsylvania, and Maryland) during spring 2007. These states were selected because they represent various climactic and soil conditions present within the region and because this study did not have the resources to survey farmers in all states. The mail survey was administered following the Dillman method (Dillman, 1978). The initial mailing took place in March 2007. A reminder postcard followed $3 \mathrm{wk}$ later. Farms that did not respond to the initial mailing were sent a second survey in April 2007, $6 \mathrm{wk}$ after the original mailing. The number of usable 
surveys returned was 1,026, including 371 from Vermont, 262 from New York, 255 from Pennsylvania, and 138 from Maryland. This resulted in a response rate of $24.5 \%$. A copy of the survey can be obtained by request to the corresponding author.

The respondents were asked to answer the questions for their farm as it was during the year 2006. The survey included questions on herd size, milk production, land use, farmer characteristics, technologies and practices, satisfaction levels with aspects of the operation, concerns for long-term survival of the farm, plans for the future of their farm, as well as feeding and grazing practices. The survey respondents were categorized into groups reflecting 3 distinct types of dairy production systems common in the Northeast and relevant to this analysis. Respondents who did not provide certain crucial information in the survey could not be categorized into a production system $(\mathrm{n}=39)$ and were deleted from the sample. Production system categories, and the number of respondents in each, are described here:

- Rotational grazing or management-intensive grazing (MIG): the milking herd gets a fresh paddock every 12 or $24 \mathrm{~h}$ and cows receive the majority of their forage intake from pasture, when adequate pasture forage is available $(\mathrm{n}=134)$.

- Large, modern confinement (LMC): the milking herd does not graze at all and the herd size (milking and dry cows) is $\geq 300(\mathrm{n}=72)$.

- Traditional (TRAD): this group includes the farms that are using pasture in a less intensive manner and confinement farms with a herd size of $<300$. This group represents farms that have not specialized into either of the preceding categories $(\mathrm{n}=781)$.

The MIG and LMC categories were chosen because they represent important newer dairy farm production systems for the Northeast. The TRAD category was extremely broad, as it contains all other responding dairy farms. The TRAD group will have many farms that have specialized in other ways than LMC or MIG. This research does not have the ability to analyze these other means of specialization. The statistical analyses reported in this paper were performed using SPSS statistical software (SPSS Inc., Chicago, IL). An $\alpha$ level of 0.05 was the criterion for significance of all statistical tests.

\section{RESULTS AND DISCUSSION}

Before presenting the results from this research, it is prudent to discuss some of its limitations. First, the survey respondents may not be truly representative of the population of dairy farmers in the Northeast for several reasons. Only 4 states in the region were sampled, because of budget constraints. Because of the small number of dairy farms in Vermont and Maryland, all dairy farms in those states were included in the sample. For New York and Pennsylvania, states with sizeable dairy farm populations, dairy farms were selected at random to be included in the sample. (The mailing lists of dairy farms in Vermont were provided by the Department of Community Development and Applied Economics at the University of Vermont; for Pennsylvania by the Bureau of Animal Health and Diagnostic Services for the Pennsylvania Department of Agriculture; for New York by the New York State Department of Agriculture and Markets; and for Maryland by the Division of Milk Control in the State Department of Health and Mental Hygiene.) Additionally, many forms of respondent bias may be present in the results. The length of the survey (6 pages of questions) and the proximity of the survey to the beginning of the spring cropping season may have hampered the response rate.

The trend toward fewer, larger dairy farms has skewed the sample and population distributions for herd size, milk production, and land area to the right. As such, the means of these variables tended to be much greater than the medians. For herd size and milk production, both mean and median are shown by state and production system in Table 1.

The mean herd size of the farms in the survey was 120 cows. This includes milking and dry cows but does not include youngstock. Vermont and New York had the largest mean herd sizes, whereas Pennsylvania had the smallest. These results are consistent with those from a similar survey implemented in 1997, which showed that Pennsylvania had significantly smaller herd sizes compared with Vermont and Virginia (Winsten et al., 2000a). New York and Maryland were not included in the 1997 survey, but Virginia was included. The mean herd size results for each state, from the current survey, was 27 to $45 \%$ greater than results reported by USDA National Agricultural Statistics Service (NASS) for 2006. Depending on how the NASS data were assembled, this may indicate that the current survey results are not truly representative of the dairy farms in these states.

The mean land area used by dairy farms in these 4 states in 2006 was 335 acres (136 ha) and the median was 218 acres per farm. The average farm in the region produced 97 acres of corn and 142 acres of hay and used 36 acres for pasture and hay and 37 acres for pasture only. On average, there were 27 acres of other crops, which were often reported to be soybeans, barley, and wheat.

The survey revealed the mean annual milk production per cow across the 4 Northeastern survey states 
Table 1. Mean (median) herd size (of milking cows) and milk production per cow (lbs/yr) by farm type ${ }^{1}$ and state

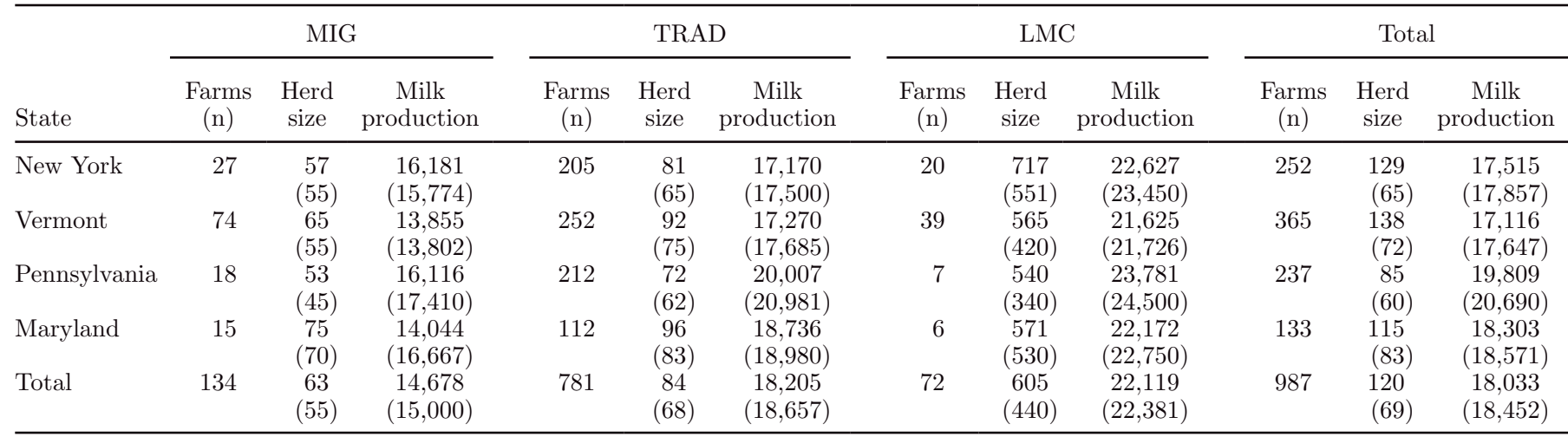

${ }^{1} \mathrm{MIG}=$ rotational grazing or management-intensive grazing; TRAD = traditional; LMC = large, modern confinement.

to be $18,033 \mathrm{lbs}(8,180 \mathrm{~kg})$ for the year 2006. Mean milk production varied widely across the states, with Pennsylvania having the highest production per cow and New York and Vermont having the lowest. As shown in the following section, New York and Vermont have a larger percentage of farms using MIG, which often results in lower milk production per cow. The 1997 survey showed that Pennsylvania had the lowest milk production per cow, indicating that Pennsylvania dairy farms seem to have made relatively larger gains in this important productivity indicator over the past 10 years. In 1997, Virginia farms had the highest milk production per cow (Winsten et al., 2000a). The current survey results for milk production per cow are within 2 to $7 \%$ of the estimates reported by NASS.

\section{Production Systems}

In 2006, the 4 survey states had $13 \%$ of dairy farms using MIG, 7\% using LMC, and the remaining $80 \%$ of dairy farms were grouped into the TRAD category. The use of MIG was up from 12 to $20 \%$ in Vermont and from 4 to $7 \%$ in Pennsylvania during the past decade (Winsten et al., 2000a). The frequency of the 3 dairy production systems varied significantly among the 4 states. For example, Vermont had the greatest percentage of farms using MIG (20\%) and LMC (10\%) and, hence, the smallest percentage in the TRAD category (70\%). In contrast, Pennsylvania had $90 \%$ of dairy farms in the TRAD category and only 7 and $3 \%$ in the MIG and LMC categories, respectively. New York and Maryland both had close to $11 \%$ of farms using MIG, but New York had twice the frequency of LMC farms (9 vs. $4.5 \%$ ) compared with Maryland.

The LMC farms had the largest median herd size by far, at 440 cows per farm. This result was expected because the definition used for LMC includes having a herd size of at least 300 cows. The MIG farms had the smallest median herd size at 55 cows per farm. Survey results showed that TRAD farms had a median herd size of 68 cows.

There were differences in mean acreage of dairy farms between the states $(F=11.584, P=0.001)$ as well as production systems $(F=324.746, P=0.001)$. The mean acreage for dairy farms in New York (437) was more than twice that for dairy farms in Pennsylvania (215), whereas Vermont and Maryland dairy farms had 346 and 328 acres, respectively. The Bonferroni correction indicated differences in farm acreage between New York and Vermont $(P=0.049)$, New York and Pennsylvania $(P=0.001)$, and Vermont and Pennsylvania $(P=0.001)$. Farms using MIG had the smallest mean land area at 217 acres, whereas TRAD farms had 268 acres and LMC farms had 1,324 acres.

Stocking density, measured as cows per acre, is an important characteristic for production as well as environmental factors. The mean stocking density across the 4 survey states was 0.47 cows per acre. Pennsylvania and Vermont farms showed the greatest stocking density ( 0.55 and 0.54 , respectively), followed by Maryland $(0.45)$ and New York (0.33). Mean stocking density was shown to be much greater for LMC farms $(0.85)$ than for MIG or TRAD farms (0.52 and 0.44, respectively).

Results of a one-way ANOVA test showed that stocking density varied between states $(F=3.536$, $P=0.014)$ and production systems $(F=7.312, P=$ $0.001)$. Pennsylvania farms had the highest mean and median stocking density of the 4 states, whereas New York farms had the lowest stocking density. The Bonferroni correction showed that the largest differences in stocking density were between New York and Vermont $(P=0.022)$ and New York and Pennsylvania $(P=$ 0.037). The LMC farms had higher stocking densities compared with MIG farms $(P=0.034)$ and TRAD farms $(P=0.001)$.

The MIG farms had lower milk production levels than TRAD farms, which had lower levels than LMC farms (Table 1). There are many possible reasons for lower 
Table 2. Frequency of use of technology and management practices reported by survey respondents by production system ${ }^{1}$

\begin{tabular}{|c|c|c|c|c|c|c|c|c|}
\hline Practice & \multicolumn{2}{|c|}{ MIG } & \multicolumn{2}{|c|}{ TRAD } & \multicolumn{2}{|c|}{ LMC } & \multicolumn{2}{|c|}{ Total } \\
\hline Milking parlor & 42 & 32.3 & 274 & 36.9 & 68 & 95.8 & 384 & 40.7 \\
\hline Automatic takeoffs & 25 & 20.3 & 259 & 35.9 & 70 & 98.6 & 354 & 38.7 \\
\hline Written nutrient plan & 57 & 45.2 & 358 & 48.5 & 66 & 93.0 & 481 & 51.4 \\
\hline Manure storage pit & 63 & 48.8 & 438 & 57.8 & 70 & 98.6 & 571 & 59.6 \\
\hline DHIA & 78 & 60.0 & 444 & 59.4 & 52 & 76.5 & 574 & 60.7 \\
\hline Artificial insemination & 118 & 90.1 & 679 & 88.3 & 70 & 97.2 & 867 & 89.2 \\
\hline Recombinant bST & 6 & 4.7 & 99 & 13.6 & 31 & 47.0 & 136 & 14.8 \\
\hline Computer for farm management & 46 & 35.9 & 231 & 31.5 & 65 & 95.6 & 342 & 36.8 \\
\hline Farm financial consultant & 24 & 19.0 & 172 & 23.8 & 55 & 80.9 & 251 & 27.4 \\
\hline Crop/nutrient management consultant & 55 & 43.3 & 387 & 52.7 & 62 & 88.6 & 504 & 54.1 \\
\hline
\end{tabular}

${ }^{1} \mathrm{MIG}=$ rotational grazing or management-intensive grazing; TRAD $=$ traditional; LMC $=$ large, modern confinement.

milk production per cow on MIG farms, such as the additional energy expended by the cows in the grazing process, the inability of producers to precisely balance feed rations for grazing animals, the amount and type of supplemental feeds provided, and the choice of breed.

\section{Technologies and Management Practices}

The frequencies of technologies and management practices are presented by production system in Table 2 . These results indicated that many of the technologies and management practices analyzed were much more frequently used by LMC farms than by MIG or TRAD farms. For example, milking parlors were the norm for the LMC production system, with a reported frequency of $96 \%$, whereas only $32 \%$ of MIG farms and $37 \%$ of TRAD farms reported using a milking parlor. Maryland was the only state in the sample where the majority of dairy farms (61\%) used a milking parlor. A similar pattern was shown for the use of a TMR, which was used by $99 \%$ of LMC farms, $57 \%$ of TRAD farms, and only $19 \%$ of MIG farms. It was not surprising that so few MIG farms used a TMR, because a TMR cannot include grazed pasture forage. Some MIG farms successfully used a small amount of TMR as part of their supplemental feeding strategy. Differences in TMR usage were observed across the states $\left(\chi^{2}=13.781, P\right.$ $=0.003)$. A TMR was used more often on farms in Maryland (68\%) than on farms in Vermont (49\%), New York $(53 \%)$, or Pennsylvania (55\%).

Only $15 \%$ of farms reported using recombinant bST $(\mathbf{r b S T})$ in their herds. This practice was less prevalent on Vermont farms $(6.8 \%)$ than on farms in any of the other states in the sample. The use of rbST was also much more prevalent on LMC farms (47\%) than on TRAD (14\%) or MIG (5\%) farms $\left(\chi^{2}=66.919, P=\right.$
0.001). Approximately $96 \%$ of LMC farms used a computer to aid in farm management compared with $36 \%$ of MIG and $32 \%$ of TRAD farms $\left(\chi^{2}=106.756, P=\right.$ 0.001). Similarly, $81 \%$ of LMC farms used a farm financial consultant compared with $24 \%$ of TRAD farms and $19 \%$ of MIG farms $\left(\chi^{2}=106.756, P=0.001\right)$. Survey respondents identified their top 3 sources of information for farm management as publications, their veterinarian, and their feed sales representative.

As environmental issues related to livestock agriculture become more prominent, it is interesting to look at variables related to manure and nutrient management on farms. Of the farms surveyed, $54 \%$ used a crop or nutrient management consultant. This was much more prevalent on LMC farms (88\%) than on MIG (43\%) or TRAD $(53 \%)$ farms $\left(\chi^{2}=40.819, P=0.001\right)$. Close to $60 \%$ of all farms surveyed had a manure storage pit located on the farm. Manure storage pits, however, were less common on New York dairy farms, at only $30 \%\left(\chi^{2}=126.62, P=0.001\right)$. As would be expected, almost $99 \%$ of LMC farms had manure storage pits $(\mathrm{MIG}=49 \%, \mathrm{TRAD}=58 \%)$. Across the region, $51 \%$ of farms had written nutrient management plans (NMP). Maryland dairy farms, however, had a much greater prevalence of NMP, at almost $96 \%\left(\chi^{2}=129.404, P=\right.$ 0.001). Maryland has one of the strictest agricultural nutrient management laws in the nation, which requires all livestock farms, regardless of size, to have an NMP (Winsten and Stokes, 2004). The greater frequency of NMP observed in this study is most certainly a result of this legislation.

The concentrated animal feeding operation (CAFO) regulations of the Clean Water Act require farms with $>700$ dairy cows to have an NMP. State-level implementation of the CAFO rules can be stricter than the federal rule, as is the case in Maryland. Given the 
CAFO rule, it is not surprising that $93 \%$ of LMC farms surveyed had a written NMP; this was true for only $49 \%$ of TRAD farms and $45 \%$ of MIG farms. The LMC farms were also more likely (64\%) to make use of custom operators for manure hauling, versus TRAD or MIG farms, both of which showed $25 \%$ of farms employing this practice $\left(\chi^{2}=47.253, P=0.001\right)$. This result was expected, because larger farms have more manure to spread during the windows of opportunity for spreading and, therefore, are more likely to need hired services that can get manure spreading done more quickly than the farm could do it.

Organic dairy production, although still a relatively small percentage of northeastern farms $(6.6 \%)$, has been a rapidly growing segment in recent years (Dalton et al., 2008). Although the costs of organic production exceed conventional costs (MacDonald et al., 2007a,b), the greater and more stable milk prices, often provided in 12- to 36-mo contracts from processors, seemed to outweigh the costs of transition, higher grain prices, and much stricter production rules for many farms. The results indicated that $12.8 \%$ of Vermont dairy farms were certified organic and 9\% were transitioning to organic production. New York followed Vermont with $4.3 \%$ certified and $3.4 \%$ transitioning to organic production. Pennsylvania had less than $3 \%$ in each category. Over $83 \%$ of the certified organic dairy farms use MIG with the remainder in the TRAD category. This was not a surprising result, because the organic dairy standards require that the animals have access to pasture. The greater prices for organic grain are likely to motivate producers to maximize nutrient intake from pasture forage by using MIG.

A large percentage of MIG farms (42\%) described a seasonal calving pattern for their herd $\left(\chi^{2}=55.628\right.$, $P=0.001)$. Of the MIG farms with a seasonal calving pattern, $53 \%$ of the herds calved in the spring and only $7 \%$ in the winter. Of the farmers with spring-calving herds, $81 \%$ reported that the primary reason for their calving pattern was to increase pasture forage intake. In contrast, the LMC farms with a seasonal calving pattern had only $14 \%$ of the herd calving in the spring and $22 \%$ calving in the winter.

\section{Farmer Characteristics}

It was also interesting to examine farmer characteristics across the region. In 2006, the average age of dairy farm operators in the Northeast was 51 yr. A one-way ANOVA failed to show that differences in operator age existed between production systems $(F=1.621, P=$ 0.198). This test did, however, indicate that differences in age existed among states $(F=8.730, P=0.001)$. Survey respondents from Pennsylvania (mean $=48, \mathrm{SD}$
$=12.65)$ tended to be younger than respondents from other states. The Bonferroni correction indicated that differences in age existed between farmers in Pennsylvania and New York $($ mean $=53, \mathrm{SD}=11.94 ; P=$ $0.001)$, Vermont $($ mean $=53, \mathrm{SD}=10.96 ; P=0.001)$, and Maryland $($ mean $=51, \mathrm{SD}=13.01 ; P=0.039)$.

Survey results also revealed that women managed less than $9 \%$ of dairy farms in the Northeast. More female respondents were managers of MIG farms (12\%) than were managers of LMC farms (5.6\%). With regard to formal education, approximately $19 \%$ of dairy farm managers had completed a bachelor's or advanced college degree. This number was $25 \%$ for Vermont managers and $7.5 \%$ for Pennsylvania managers, which is probably because of the higher percentage of Amish farmers in Pennsylvania, for whom formal education often ends before the completion of high school. When looking at formal education by production system, the frequency of a bachelor's or advanced college degree was lower among managers of TRAD farms (16\%) than for LMC farms $(34 \%)$ or MIG farms $(31 \%)\left(\chi^{2}=27.921, P=\right.$ $0.001)$.

Survey respondents were asked to rate their satisfaction with 8 aspects of their dairy farm operations. The mean satisfaction level for each aspect can be seen in Figure 4. Differences between production systems seemed to exist with regard to satisfaction levels with various aspects of the farming operations. Farmers using MIG or LMC systems indicated greater satisfaction with the financial progress of their operation over the past $5 \mathrm{yr}$ than did farmers using TRAD systems $\left(\chi^{2}=\right.$ $14.654, P=0.001$ ). Based on previous studies of farm financial performance, it was assumed that satisfaction with the MIG system comes primarily from the reduction in operating costs, such as feed, fuel, utilities, and veterinary expenses associated with rotational grazing (Ostrom and Jackson-Smith, 2000; Winsten et al., 2000b). For a small percentage of MIG farms, it is likely that financial progress was accelerated by reducing fixed costs through divestment of equipment and infrastructure that was not needed for a pasture-only or seasonal milking production system. For farmers using LMC systems, it is possible that financial progress was the result of successfully capturing economies of scale.

The Kruskal-Wallis ANOVA compared the mean satisfaction rankings among farmers of the production systems (Table 3 ). The test revealed that farmers using LMC were highly satisfied with the amount of time that they spent away from the farm $\left(\chi^{2}=10.177, P\right.$ $=0.006)$. This is most likely related to having more labor on the farm, which allows the operator to take regular days off. One of the most striking differences in satisfaction level was related to herd health, for which farmers using MIG reported far greater satisfaction 


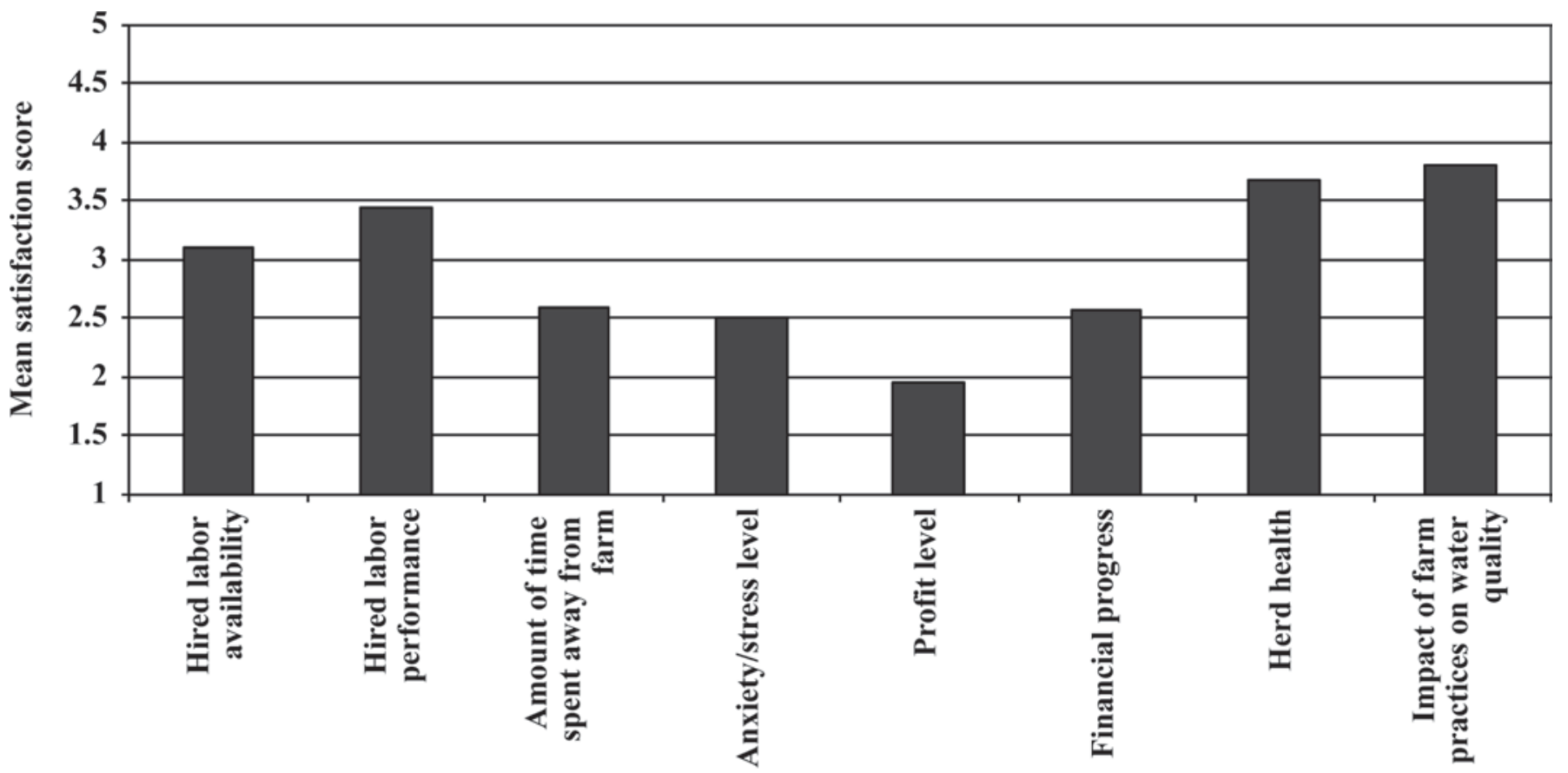

Aspects of farmer satisfaction with operation

Figure 4. Average farmer scores for satisfaction with various aspects of their dairy farm operations. Score categories: $1=$ very dissatisfied; $5=$ very satisfied

than farmers in either of the other groups $\left(\chi^{2}=24.678\right.$, $P=0.001$ ).

On the issue of the farm's effect on water quality, MIG and LMC farmers tended to be more satisfied than TRAD farmers $\left(\chi^{2}=6.658, P=0.036\right)$. With regard to MIG, the fact that permanent vegetative cover helps to reduce soil erosion may be responsible for the perception of MIG farmers that they have less impact on water quality. It may be the case, however, that surface-applied manure from grazing animals results in higher dissolved $\mathrm{P}$ delivery to streams (Sharpley and Beegle, 1999). For LMC farms, the much greater likelihood of having an NMP for the farm may increase LMC farmers' satisfaction level with this issue.

When considering the future of the dairy industry in the Northeast, understanding farmers' concerns for the survival of their farm is of paramount importance. The results from this survey indicate some interesting differences across the production systems regarding the types and levels of concerns that farmers have. In the survey, farmers were asked to indicate their level of concern for the survival of their dairy farm over the next 5 yr related to specific factors. Again, the KruskalWallis ANOVA was used to compare the mean ranks among the production systems (Table 4). Most notable was that MIG farmers were much less concerned about the price of milk received than were farmers in either of the other groups $\left(\chi^{2}=17.598, P=0.001\right)$. Some of this reduced concern may stem from the contingent of MIG farms that were selling organic milk at a fixed and premium price, but may be a result of reduced costs of production, which would allow MIG farms to remain profitable at lower milk prices relative to the other systems. A similar conclusion can be reached from the result that MIG farmers were less concerned than other farmers over the costs of milk production on the farm $\left(\chi^{2}=6.105, P=0.047\right)$.

Farmers using LMC were more concerned than TRAD farmers about their current herd size remaining viable $5 \mathrm{yr}$ into the future $\left(\chi^{2}=6.891, P=0.032\right)$. This is a curious result, because LMC farms, by definition, have a herd size in excess of 300 milking cows. This result may also reflect the cost structure and profit margin of LMC farms relative to those in the TRAD group. Farmers using MIG were significantly less concerned about the viability of their current herd size than either of the other groups.

This pattern of greatest concern among LMC farmers followed by TRAD farmers and lesser concern among MIG farmers also extends to issues of land availability $\left(\chi^{2}=14.237, P=0.001\right)$, the costs of farm expansion $\left(\chi^{2}=11.985, P=0.002\right)$, and taking on more debt $\left(\chi^{2}=7.468, P=0.024\right)$. Consistency in the level of concern across these issues is logical, because each issue 
Table 3. Results of the Kruskal-Wallis test of differences in satisfaction with aspects of farm operations among farm production systems

\begin{tabular}{|c|c|c|c|c|c|}
\hline Aspect of farm operations & Production system ${ }^{1}$ & $\mathrm{n}$ & Mean $\operatorname{rank}^{2}$ & $\chi^{2}$ & $P$-value \\
\hline \multirow{2}{*}{ Hired labor availability } & TRAD & 697 & 438.54 & \multirow{2}{*}{1.146} & \multirow{2}{*}{0.564} \\
\hline & LMC & 72 & 455.39 & & \\
\hline \multirow{2}{*}{ Hired labor performance } & TRAD & 682 & 422.73 & \multirow{2}{*}{4.570} & \multirow{2}{*}{0.006} \\
\hline & LMC & 69 & 470.43 & & \\
\hline Amount of time away from farm & MIG & 132 & 471.77 & 10.177 & 0.006 \\
\hline \multirow[t]{3}{*}{ Anxiety/stress level } & MIG & 133 & 526.03 & \multirow{3}{*}{4.799} & \multirow[t]{3}{*}{0.091} \\
\hline & TRAD & 753 & 471.20 & & \\
\hline & LMC & 71 & 473.61 & & \\
\hline \multirow[t]{3}{*}{ Profit level } & MIG & 132 & 535.44 & \multirow[t]{3}{*}{5.283} & \multirow[t]{3}{*}{0.071} \\
\hline & TRAD & 771 & 480.77 & & \\
\hline & LMC & 71 & 471.42 & & \\
\hline Financial progress & MIG & 132 & 542.26 & 14.654 & 0.001 \\
\hline \multirow{3}{*}{ Impact of farm practices on water quality } & MIG & 132 & 537.45 & \multirow[t]{3}{*}{6.658} & \multirow[t]{3}{*}{0.036} \\
\hline & TRAD & 773 & 477.84 & & \\
\hline & LMC & 72 & 520.03 & & \\
\hline
\end{tabular}

${ }^{1} \mathrm{MIG}=$ rotational grazing or management-intensive grazing; TRAD = traditional; LMC = large, modern confinement.

${ }^{2}$ The Kruskal-Wallis test uses the sum of ranks for each group as well as the averages. Ranks based on categories 1 to 5 , where $1=$ very dissatisfied and $5=$ very satisfied. A higher mean rank indicates that group has greater satisfaction with that particular aspect of the farm operations.

is related to the size of the farming operation in the near future. Because the LMC farms use more hired labor, it makes sense that these farmers were more concerned than either TRAD or MIG farmers about the issue of labor availability $\left(\chi^{2}=25.950, P=0.001\right)$, which is an increasingly difficult issue in many parts of the Northeast.

Concerns over current and future regulations imposed on dairy farms regarding environmental quality show that MIG farmers were much less concerned than TRAD farmers, who were much less concerned than LMC farmers $\left(\chi^{2}=13.495, P=0.001\right)$. The heightened concern among LMC farmers is most likely a result of the current regulatory context that has singled out CAFOs and subjected them to rigorous demands.

What do these results mean for the future of the dairy industry in the northeastern United States? Although the responses captured in this survey will have been affected by personal values, personality types, drive, and risk tolerance levels, the survey results suggest that MIG farmers may be less likely to exit the industry in the next 5 yr $(12.1 \%)$ compared with LMC farmers $(17.2 \%)$ and TRAD farmers $(18.6 \%)$. There are several reasons that LMC farms may not be likely to transition to MIG. These include lifestyle choice, income, and existing investment in confinement-feeding infrastructure. Some of the TRAD farms, however, may have an interest in using MIG. One policy implication of these results is that programs to help TRAD farmers evaluate and consider adopting MIG may be a worthwhile investment in the future of the northeastern dairy industry.

\section{CONCLUSIONS}

Information gathered from 987 northeastern dairy farmers provided an interesting snapshot of the industry's structure. The results, compared with a similar survey from 1996, suggested that the trend toward specialization continues. As of 2006, $13 \%$ of farms were using management-intensive grazing or MIG (capitalizing on reduced input costs) and $7 \%$ of farms were using large, modern confinement-feeding systems or LMC (capitalizing on increased volume of production). Mean milk production per cow on LMC farms was $21 \%$ greater than on traditional dairy farms and $45 \%$ greater than on MIG farms. The LMC farms were more likely to be using production technologies and services such as a milking parlor, rbST, computers, and consultants for financial and crop management. Related to environmental factors, LMC farms, on average, had a greater stocking density, but were more likely to have manure storage facilities and written nutrient management plans. Farmers using MIG indicated less likeli- 
Table 4. Results of the Kruskal-Wallis test of differences among farm production systems in farmer's concerns for the future viability of their farm

\begin{tabular}{|c|c|c|c|c|c|}
\hline Concern for future & Production system ${ }^{1}$ & $\mathrm{n}$ & Mean $\mathrm{rank}^{2}$ & $\chi^{2}$ & $P$-value \\
\hline \multirow{2}{*}{ Milk price } & TRAD & 788 & 505.58 & & \\
\hline & LMC & 73 & 539.64 & & \\
\hline \multirow{2}{*}{ Milk production costs } & TRAD & 785 & 502.61 & & \\
\hline & LMC & 73 & 505.74 & & \\
\hline Farm profitability & MIG & 133 & 462.83 & 3.491 & 0.175 \\
\hline \multirow{2}{*}{ Environmental regulations } & TRAD & 783 & 492.47 & & \\
\hline & LMC & 71 & 592.54 & & \\
\hline \multirow{3}{*}{ Continuing the farm to next generation } & MIG & 133 & 483.88 & 0.516 & 0.773 \\
\hline & TRAD & 777 & 495.05 & & \\
\hline & LMC & 73 & 474.38 & & \\
\hline Real-estate taxes & MIG & 133 & 499.67 & 4.776 & 0.092 \\
\hline \multirow[t]{3}{*}{ Current herd size } & MIG & 133 & 443.12 & 6.891 & 0.032 \\
\hline & TRAD & 781 & 498.44 & & \\
\hline & LMC & 73 & 539.16 & & \\
\hline \multirow[t]{3}{*}{ Land availability } & MIG & 131 & 435.18 & 14.237 & 0.001 \\
\hline & TRAD & 783 & 494.55 & & \\
\hline & LMC & 72 & 588.23 & & \\
\hline \multirow[t]{3}{*}{ Costs of farm expansion } & MIG & 133 & 430.98 & 11.985 & 0.002 \\
\hline & TRAD & 776 & 494.89 & & \\
\hline & LMC & 73 & 565.75 & & \\
\hline \multirow[t]{3}{*}{ Taking on more debt } & MIG & 132 & 434.81 & 7.468 & 0.024 \\
\hline & TRAD & 780 & 499.93 & & \\
\hline & LMC & 73 & 524.12 & & \\
\hline \multirow[t]{2}{*}{ Labor availability } & MIG & 128 & 455.02 & 25.950 & 0.000 \\
\hline & TRAD & 769 & 476.02 & & \\
\hline
\end{tabular}

${ }^{1} \mathrm{MIG}=$ rotational grazing or management-intensive grazing; TRAD = traditional; LMC = large, modern confinement.

${ }^{2}$ The Kruskal-Wallis test uses the sum of ranks for each group as well as the averages. Ranks are based on categories 1 to 5 , where $1=$ not a concern and $5=$ significant concern. A higher mean rank indicates that particular aspect of the farm operations is a cause for great concern for a specific group.

hood of exiting the industry in the coming 5 yr. How the trend in the structure of the dairy industry plays out in future years will have an important effect on the health and character of the region's rural communities. Understanding the potential impacts, on environmental quality, rural communities, and the food system, of the changing dairy industry is an important area for future research.

\section{ACKNOWLEDGMENTS}

Winrock International conducted this research in conjunction with the University of Vermont. The National Research Initiative of the USDA Cooperative State Research, Education, and Extension Service supported this project under grant number 2006-55618-17016. The authors express their gratitude to the many farm- ers who took the time to provide valuable information by completing the survey, as well as to the staff of the Center for Rural Studies at the University of Vermont in Burlington for help with survey design.

\section{REFERENCES}

Berghaus, R. D., B. J. McCluskey, and R. J. Callan. 2005. Risk factors associated with hemorraghic bowel syndrome in dairy cattle. J. Am. Vet. Med. Assoc. 226:1700-1706.

Blayney, D. P. 2002. The changing landscape of U.S. milk production. Statistical Bull. No. 978. USDA-ERS, Washington, DC.

Dalton, T. J., R. Parsons, R. Kersbergen, G. Rogers, D. Kauppila, L. McCrory, L. A. Bragg, and Q. Wang. 2008. A comparative analysis of organic dairy farms in Maine and Vermont: Farm financial information from 2004-2006. ISSN 1070-1494. Bull. No. 851. Maine Agricultural and Forest Experiment Station, The University of Maine, Orono.

Dillman, D. A. 1978. Mail and Telephone Surveys: The Total Design Method. Wiley-Interscience, New York, NY. 
Goldberg, J. J., E. E. Wildman, J. W. Pankey, J. R. Kunkel, D. B. Howard, and B. M. Murphy. 1992. The influence of intensively managed rotational grazing, traditional continuous grazing and confinement housing on bulk milk quality and udder health. J. Dairy Sci. 75:96-104.

Green, M. J., A. J. Bradley, G. F. Medley, and W. J. Browne. 2007. Cow, farm and management factors during the dry period that determine the rate of clinical mastitis after calving. J. Dairy Sci. 90:3764-3776.

Hassanein, N. 1999. Changing the way America farms: Knowledge and community in the sustainable agriculture movement. University of Nebraska Press, Lincoln.

Hernandez-Mendo, O., M. A. G. von Keyserlingk, D. M. Veira, and D. M. Weary. 2007. Effects of pasture on lameness in dairy cows. J. Dairy Sci. 90:1209-1214.

Jackson-Smith, D., B. Barham, M. Nevius, and R. Klemme. 1996. Grazing in Dairyland: The Use and Performance of Management Intensive Rotational Grazing among Wisconsin Dairy Farms. Tech. Rep. No. 5 (November). Agricultural Technology and Family Farm Institute, University of Wisconsin, Madison.

MacDonald, J. M., W. D. McBride, and E. J. O'Donoghue. 2007a. Low costs drive production to large dairy farms. Amber Waves. Vol 5(4). US Department of Agriculture Economic Research Service, Washington, DC.

MacDonald, J. M., E. J. O'Donoghue, W. D. McBride, R. F. Nehring, C. L. Sandretto, and R. Mosheim. 2007b. Profits, costs, and the changing structure of dairy farming. Economic Research Report Number 47. United States Department of Agriculture Economic Research Service, Washington, DC

Onyiro, O. M., and S. Brotherstone. 2008. Genetic analysis of locomotion and associated conformation traits of Holstein-Friesian dairy cows managed in different housing systems. J. Dairy Sci. 91:322-328.
Ostrom, M. R., and D. B. Jackson-Smith. 2000. The use and performance of management- intensive rotational grazing among Wisconsin dairy farms in the 1990's. Program on Agricultural Technology Studies (PATS) Research Report No. 8. University of Wisconsin-Extension, Madison.

Paine, L. K., R. M. Klemme, D. J. Undersander, and M. Welsh. 2000. Wisconsin's grazing networks: History, structure, and function. J. Nat. Resour. Life Sci. Educ. 29:60-67.

Parker, W. J., L. D. Muller, S. L. Fales, and W. T. McSweeny. 1993. A survey of dairy farms in Pennsylvania using minimal or intensive pasture grazing systems. Prof. Anim. Sci. 9:159-165.

Renfrew, R. B., and C. A. Ribic. 2001. Grassland birds associated with agricultural riparian practices in southwestern Wisconsin. J. Range Manage. 54:546-552.

Sharpley, A. N., and D. B. Beegle. 1999. Managing Phosphorus for Agriculture and the Environment. The Pennsylvania State University, University Park.

Thomsen, P. T., A. M. Kjeldsen, J. T. Sorenson, H. Houe, and A. K. Ersboll. 2006. Herd-level risk factors for mortality of cows in Danish dairy herds. Vet. Rec. 158:152-156.

USDA NASS (National Agricultural Statistics Service). 2009. Quick Stats Database. http://www.nass.usda.gov/Data_and_Statistics/ Quick_Stats/index.asp\#top Accessed October 2009.

Winsten, J. R., R. L. Parsons, and G. D. Hanson. 2000a. Differentiated dairy grazing intensity in the northeast. J. Dairy Sci. 83:836842.

Winsten, J. R., R. L. Parsons, and G. D. Hanson. 2000b. A profitability analysis of dairy farms and feeding systems in the northeast. Agric. Resour. Econ. Rev. 29:220-228.

Winsten, J. R., and J. R. Stokes. 2004. The efficacy of controlling phosphorus loading: The case of management-intensive grazing. Agric. Syst. 79:283-303. 